\title{
Local anesthesia for Reduction of Nasal Bone Fracture: our experience
}

\author{
Aljfout $\mathbf{Q}^{1}$, Al-Btoush $\mathrm{A}^{2}$, Alrefo $\mathrm{A}^{3}$, Al-Soud $\mathbf{N}^{4}$, Obeidat $\mathbf{T}^{5}$ \\ ${ }^{1}$ Dr Qais Aljfout, Otorhinolaryngology Department, ${ }^{2} \mathrm{Dr}$ Ahmed AL-Btoush, Otorhinolaryngology Department, \\ ${ }^{3}$ Dr. Abdelrazzaq Alrefo, Otorhinolaryngology Department, ${ }^{4} \mathrm{Dr}$ Nidal Al-Soud, Anesthesia Department, \\ ${ }^{5}$ Dr Tamara.a.Obeidat, Radiology Department, all authors are affiliated with Royal Medical Services, Amman- Jordan.
}

Address for Correspondence: Dr Qais Aljfout, Senior Specialist Otorhinolaryngology, Head \& Neck Surgery Royal Medical Services, Tareq, Amman 11947 Jordan, Email: qaisj@yahoo.com

\begin{abstract}
Introduction: Nasal bone fractures are very common injuries, reduction under local anesthesia is the usual management, yet there is controversy about the efficacy of this management and if it satisfies the patient's functional and cosmetic needs. Objective: To assess both efficacy of nasal bone reduction under local anesthesia and patient's degree of satisfaction in regards to aesthetic and functional results. Patients and Methods: Retrospective analysis and review of 31 patients underwent nasal bone reduction under local anesthesia in Prince Hashim Military hospital in Zarqa, Jordan between May 2015 and June 2016. Digital and instrumental reduction under local anesthesia was performed with and without splint application after clinical and radiological assessment. Results were evaluated by objective clinical examination and subjective functional and cosmetic satisfaction. Results: Patients were divided into two groups according to gender, group A: males 23 (74.19\%), group B: females 8 (25.8\%), 20 patients of group A (86.95\%) were happy with the functional and cosmetic outcome, 3 patients of group A (13.04\%) were not happy with the cosmetic outcome but happy regarding the functional outcome, 5 patients of group B were happy with the functional and cosmetic outcome, 3 patients of group B were not happy regarding the cosmetic outcome but satisfied with the functional outcome, all patients in both groups except one patient in group A were had patent nasal airway on clinical and endoscopic examination. 2 patients from both groups sought revision surgery for cosmetic concerns only. Conclusion: Use of local anesthesia for reduction of nasal bone fractures offers both patent nasal airway and satisfactory cosmetic results.
\end{abstract}

Key words: Fractures, Local anesthesia, Nasal bone, Reduction, Satisfaction

\section{Introduction}

Nasal bone fracture is one of the common injuries due to trauma, and reports consider it the third common injury and the most commonly injured facial bone $[1,2]$, usually these fractures are undertreated which might result in a significant long term problems for the patient from both aspects; functional and cosmetic [3]. Primary closed reduction is considered to be the preferred management option for nasal bone fractures in the acute phase [4,5], inadequate or unsatisfactory results regarding both functional and cosmetic outcome generally appear due to the lack of technical expertise, improper or under evaluation of the extent of the fracture, both are usually attributed to presence of junior

Manuscript received: $18^{\text {th }}$ January 2017

Reviewed: $27^{\text {th }}$ January 2017

Author Corrected: $6^{\text {th }}$ February 2017

Accepted for Publication: $13^{\text {th }}$ February 2017 doctors in the emergency room, delays in treatment and in some cases limited resources, and all of these factors might result in a revision surgery in these patients [6,7]. In our practice, primary reduction under local anesthesia is the rule, and we have conducted this study to evaluate efficacy of reduction under local anesthesia with regards to functional and cosmetic results.

\section{Methods}

This is a retrospective analysis of clinical records of 31 patients aged 15 to 63 years who were diagnosed with nasal bone fractures and were treated by closed reduction under local anaesthesia by the ENT doctors in Prince Hashem Military hospital between May 2015 and June 2016. Diagnosis was confirmed after clinical and radiological assessment which includes plain 
radiographs and in some cases computed tomography scans because the plain radiographs were not helpful in the diagnosis or patient had other injuries that required CT scan.

After documentation of the deformity, both nostrils sprayed by topical anesthetic nasal spray, and subcutaneous injection $1-2 \mathrm{ml}$ of $2 \%$ lidocain with adrenaline solution $(1: 200,000)$ was made down both sides of the nose by a single or two punctures of the skin at the level of the glabella in order to anesthetise both external nasal nerves, reduction was done after 5 minutes after checking the adequacy of the anaesthesia. Digital pressure reduction used in more than $60 \%$ of the cases as the only technique, instrumental reduction was used in $40 \%$ of the cases especially with the depressed type of displacement; the aim of the instrumental reduction was restore the symmetry of the nasal pyramid and its midline alignment.

Patients were divided into two groups according to gender, group A consisted of male patients and group B consisted of female patients. Clinical records abstract form was designed to collect our study data which includes, age, gender, cause of injury, type of imaging, and final outcome depending on clinical and endoscopic examination and subjective values based on a visual analogue scores provided to the patients, evaluating their satisfaction both functional and cosmetic.

\section{Results}

Patients were divided into two groups, group A composed of 23 male patients (74.19\%), with mean age $38.6 \pm 13.8$ years, and group B composed of 8 female patients with a mean age of $32.4 \pm 11.8$ years.

In 19 patients $(83 \%)$ of group A and 5 patients of group B, diagnosis was confirmed by a plain radiograph. CT scan confirmed diagnosis in 4 patients of group A and 3 patients of group B. 20 patients of group A (87\%) were happy with the functional and cosmetic outcome, 2 patients of group A $(9 \%)$ were not happy with the cosmetic outcome but happy regarding the functional outcome and one patient (4\%) was not satisfied with both functional and cosmetic results. 5 patients of group B were happy with the functional and cosmetic outcome, 2 patients of group B were not happy regarding the cosmetic outcome but satisfied with the functional outcome, and one patient was not satisfied with both functional and cosmetic results. 2 patients from both groups sought revision surgery for cosmetic concerns only (table 1).

Table-1: Analysis data of our study groups.

\begin{tabular}{|c|c|c|}
\cline { 2 - 3 } \multicolumn{1}{c|}{} & Group A & Group B \\
\hline Age & $\mathbf{3 8 . 6} \pm \mathbf{1 3 . 8}$ years & $\mathbf{3 2 . 4} \pm \mathbf{1 1 . 8}$ years. \\
\hline Plain radiograph & $19(83 \%)$ & 3 \\
\hline CT scan & $4(17 \%)$ & 5 \\
\hline Satisfaction both & $20(87 \%)$ & 2 \\
\hline Functional only & $2(9 \%)$ & 1 \\
\cline { 2 - 3 } Neither & $1(4 \%)$ & $\mathbf{8}$ \\
\cline { 2 - 3 } & $\mathbf{2 3}$ & 5 \\
\hline Total No. & &
\end{tabular}

\section{Discussion}

Nasal bone fracture is one of the common injuries that are encountered almost daily in emergency room and it accounts for nearly $40 \%$ of facial bone injuries [1] and these fractures are more common in adult males since they are more commonly involved in fights, sports injuries and road traffic accidents which are the main causes for such a trauma. Being the most prominent and anterior part of the face, the Nose is easily traumatized and fractured, these fractures might be isolated to the nasal bone or could be in association with other facial and body bony injuries. Aesthetic- functional correction of a fractured nasal bone is the ultimate goal in management of these fractures and although surgical management differs according to the technique used whether open or closed, and according to the type of anesthesia used which might be general, local infiltration, topical gel as tetracaine and intranasal cocaine solution [8]. 
In our study the most common causes for the nasal injuries were in descending order: sport injuries, road traffic accidents, accidental falling down and the least common cause are being involved in fights.

Patients were examined and evaluated in ENT clinic using physical and endoscopic examination then underwent radiological evaluation to be classified to: displacement fractures $(77 \%)$, depressed fractures (16\%), non-deformity fractures $(7 \%)$.

Regarding the imaging techniques used in this study, plain radiographs were used as an initial radiological assessment for medico legal purposes even that many studies stated that plain radiographs are not helpful in the diagnosis of nasal bone fractures because it fail to detect a clinically evident fractures in about $50 \%$ of the cases $[4,9]$. Computed scan used in cases were multiple facial injuries are suspected and in sever nasal trauma as a map for the reduction [10].

Results showed significant patients satisfaction and good efficacy of using the local anaesthesia for closed nasal bone fracture reduction in agreement with many other studies supporting the use of local anaesthesia to avoid the risks and complication of general anaesthesia [11-13], and to decrease the cost of the reduction procedure which was an important factor in avoidance of seeking medical help for such nasal injuries [14], while others had advocated the use of endonasal incision in some cases [15].

\section{Conclusion}

Nasal bone fracture reduction under local anesthesia has excellent levels of satisfaction regarding both functional and cosmetic outcome. Therefore, factors like proper evaluation of the extent of the fracture and correct treatment timing should be respected to minimize the risk of failure and avoid revision surgery.

\section{Funding: Nil, Conflict of interest: None. Permission of IRB: Yes}

\section{References}

1. Kim MG, Kim BK, Park JL, Minn KW, Baek RM, Han KN. The use of bioabsorbable plate fixation for nasal fractures under local anaesthesia through open lacerations. J Plast Reconstr Aesthet Surg. 2008 Jun; 61(6): 696-9. doi: 10.1016/j.bjps. 2006.12.005. Epub 2007 Jan 31.
2. Smith JA. Nasal emergencies and sinusitis. Tintinalli JE, Ruiz E, Krome RL, eds. Emergency Medicine: A Comprehensive Study Guide. 4th ed. New York, NY: McGraw-Hill Publishing; 1996. 1087-91.

3. Atighechi S, Karimi G. Serial nasal bone reduction: a new approach to the management of nasal bone fracture. J Craniofac Surg. 2009 Jan;20(1):49-52. doi: 10. 1097/SCS.0b013e318190def5.

4. Rohrich RJ, Adams WP Jr. Nasal fracture management: minimizing secondary nasal deformities. Plast Reconstr Surg. 2000 Aug;106(2):266-73.

5. Ridder GJ, Boedeker CC, Fradis M, Schipper J. Technique and timing for closed reduction of isolated nasal fractures: a retrospective study. Ear Nose Throat J. 2002 Jan;81(1):49-54.

6. Hwang K, You SH, Kim SG, Lee SI. Analysis of nasal bone fractures; a six-year study of 503 patients. J Craniofac Surg. 2006 Mar;17(2):261-4.

7. Fattahi T, Steinberg B, Fernandes R, Mohan M, Reitter E. Repair of nasal complex fractures and the need for secondary septo-rhinoplasty. J Oral Maxillofac Surg. 2006;64(12):1785-9. Repair of nasal complex fractures and the need for secondary septo-rhinoplasty. J Oral Maxillofac Surg. 2006 Dec;64(12):1785-9.

8. Jones TM, Nandapalan V. Manipulation of the fractured nose: a comparison of local infiltration anaesthesia and topical local anaesthesia. Clin Otolaryngol Allied Sci 1999;24(5):443-446.

9. Kucik CJ, Clenney T, Phelan J. Management of acute nasal fractures. Am Fam Physician. 2004 Oct 1;70 (7):1315-20.

10. Han DS, Han YS, Park JH. A new approach to the treatment of nasal bone fracture: radiologic classification of nasal bone fractures and its clinical application. J Oral Maxillofac Surg. 2011 Nov; 69 (11):2841-7. doi: 10.1016/j.joms.2011.01.013. Epub 2011 Apr 7.

11. Chadha NK, Repanos C, Carswell AJ. Local anaesthesia for manipulation of nasal fractures: systematic review. J Laryngol Otol. 2009 Aug; 123 (8):830-6. doi: 10.1017/S002221510900560X. Epub 2009 May 27. 
12. Waldron J, Mitchell DB, Ford G (1989) Reduction of fractured nasal bones; local versus general anaesthetic. Clinical Otolaryngology e. Otolaryngologic Clinics of North America 8: 663-677.

13. Erdmann D, Follmar KE, Debruijn M, Bruno AD, Jung SH, Edelman D, Mukundan S, Marcus JR. A retrospective analysis of facial fracture etiologies. Ann Plast Surg. 2008 Apr;60(4):398-403. doi: 10.1097/SAP. 0b013e318133a87b.
14. Rohrich RJ, Adams WP Jr. Nasal fracture management: minimizing secondary nasal deformities. Plast Reconstr Surg. 2000 Aug;106(2):266-73.

15. Kim HS, Suh HW, Ha KY, Kim BY, Kim TY. The usefulness of the endonasal incisional approach for the treatment of nasal bone fracture. Arch Plast Surg. 2012 May; 39 (3):209-15. doi: 10.5999/aps.2012.39.3.209. Epub 2012 May 10.

\section{How to cite this article?}

Aljfout Q, Al-Btoush A, Alrefo A, Al-Soud N, Obeidat T. Local anesthesia for Reduction of Nasal Bone Fracture: our experience. Int J Med Res Rev 2017;5(02):124-127. doi:10.17511/ijmrr. 2017.i02.05. 